\title{
A Cross-sectional Study to Estimate the Prevalence of Dyslipidaemia in Patients with Cholelithiasis
}

\section{ABSTRACT}

Introduction: Gallstones are one among the common gastrointestinal illness requiring hospitalisation and frequently occur in middleaged otherwise healthy people with a prevalence of 10 to $15 \%$. Women are more frequently affected than men. Most patients remain asymptomatic from their gallstones and remain silent throughout life. One major factor contributing to cholesterol stone formation is high concentration of cholesterol and lipids in bile secretion from liver. Changes in human behaviour and lifestyle over the last few decades have resulted in a dramatic increase in the incidence of dyslipidaemia and gallstone disease worldwide.

Aim: To estimate the prevalence of dyslipidaemia in patients with gallstones.

Materials and Methods: A cross-sectional study was done on 82 patients who were admitted in a tertiary care centre with gall stone confirmed by ultrasound abdomen, during the period between November 2016 to October 2017. Patients with dyslipidaemia taking medicine were excluded. Data were entered in structured data sheet which includes all the variables and results were expressed in frequency and percentage.

Results: Forty-two patients were found to have dyslipidaemia and the prevalence was found to be $51.2 \%$. Maximum prevalence of cholelithiasis was found in the $41-50$ years age group (58.5\%). Fifty-six were females (68.3\%). Twenty-four patients had very high Serum Low Density Lipoprotiens (LDL) levels. Twenty-three had high levels of Triglycerides (TG) $(28 \%)$. Six had very low High Density Lipoprotein (HDL) level (7.3\%).

Conclusion: The prevalence of dyslipidaemia estimated was $51.2 \%$. Of the fractions of serum lipids, the LDL and triglycerides level elevations was more commonly detected in patients with gall stone.

\section{INTRODUCTION}

Gall stone are one of the common causes of gastrointestinal illness. This occurs more frequently in middle aged healthy individuals. The reported prevalence is 10 to $15 \%$ [1,2]. Women are commonly affected than men [3]. Most of the individuals with gall stones do not present with symptoms and remain silent. Aetiological factors for gall stone formation are super saturation of secreted bile, concentration of bile in the gallbladder, accelerated nucleation, accumulation of mucin and hypomotility of gallbladder [4]. The most important factor in the formation of cholesterol stone is high concentration of cholesterol and lipids [5,6] in bile secretion from liver. Changes in human behaviour and lifestyle over the last few decades have resulted in a dramatic increase in the incidence of dyslipidaemia and gallstone disease worldwide. There is controversy regarding association of dyslipidaemia and gall stone formation. Studies have shown increased occurrence of gall stone in dyslipidaemia patients $[7,8]$ and studies have not shown increased association $[9,10]$ are available in the literature. Hence, present study was conducted with aim to estimate the prevalence of dyslipidaemia in patients with gallstones.

\section{MATERIALS AND METHODS}

The present cross-sectional study was done on patients admitted with cholelithisis at Government Medical College, Thrivanthrampuram, Kerala, India a tertiary care centre in South India. Ethical committee clearance was taken (IEC No 04/14/2017/MCT). Informed consent was taken from each patients and confidentiality was maintained.

Inclusion criteria: All ultrasound proven cases of cholelithiasis admitted for cholecystectomy during the stated period were included.

Exclusion criteria: Patients with history of dyslipidaemia on treatment for more than three months were excluded.
Consecutive 82 cases meeting the eligibility were included within the sample frame of time from November 2016 to October 2017. Blood was drawn from all patients for lipid profile analysis. Dyslipidaemia was defined as either increased level of LDL or TG above normal level or decreased level of HDL below normal [11]. Total cholesterol below 200 mg was taken as normal, 200 to 239 was categorised as borderline and above 240 was high. LDL level below 100 was taken as low, 100 to 129 was borderline,130 to 159 was high and above 160 was very high. The triglycerides level below 150 was taken as normal, 150 to 199 was borderline, 200 to 499 was high and above 500 was very high. The HDL level below 40 was taken as very low, 40 to 59 was low and above 60 was normal [11].

\section{STATISTICAL ANALYSIS}

Data were entered in structured data sheet which includes all the variables and results were expressed in frequency and percentage.

\section{RESULTS}

The most common age group affected in the study was 41 to 50 years that constitute $58.5 \%$. The mean age was 49.4 years with standard deviation of 3.9 [Table/Fig-1]. Of the studied population 56 were females and 26 were males. Diabetes mellitus was present in 29 and 43 were obese, 27 had hypertension and five had coronary artery disease.

\begin{tabular}{|c|c|c|}
\hline Age (years) & Number & Percent \\
\hline $41-50$ & 48 & 58.5 \\
\hline$>50$ & 34 & 41.5 \\
\hline Mean \pm SD & \multicolumn{2}{|c|}{$49.4 \pm 3.9$} \\
\hline
\end{tabular}


In this study, out of 82 patients studied, 42 patients were found to have dyslipidaemia and the prevalence derived is $51.2 \%$ and 40 had normal serum lipid levels [Table/Fig-2]. In the studied population 28 patients were found to have serum cholesterol level above $240 \mathrm{mg}$ (34.1\%), 14 had serum cholesterol level between 200 and $240 \mathrm{mg}(17.1 \%)$ and 40 (48.8\%) patients had normal serum cholesterol levels, the mean cholesterol was $216.9 \pm 34.5 \mathrm{mg}$. The serum LDL level were very high in 24 patients (29.3\%), 18 had high levels (22\%), 26 had borderline levels (31.7\%) and 14 had low levels of serum LDL (17.1\%) [Table/Fig-3]. Serum triglycerides level was found very high in 23 (28\%) and 38 (46.3\%) had normal levels [Table/Fig-4]. The level of HDL was found to be below normal level in six patients (7.3\%) [Table/Fig-5].

\begin{tabular}{|l|c|c|c|}
\hline Dyslipidaemia & Number & Percent & $95 \% \mathrm{Cl}$ \\
\hline Yes & 42 & 51.2 & \multirow{2}{*}{$40.4-62$} \\
\cline { 1 - 3 } No & 40 & 48.8 & \\
\hline
\end{tabular}

\begin{tabular}{|l|c|c|}
\hline LDL (mg/dL) & Number & Percent \\
\hline Low & 14 & 17.1 \\
\hline Borderline & 26 & 31.7 \\
\hline High & 18 & 22.0 \\
\hline Very high & 24 & 29.3 \\
\hline Mean \pm SD & \multicolumn{2}{|c|}{$130.9 \pm 30.5$} \\
\hline
\end{tabular}

[Table/Fig-3]: Percentage distribution of the sample according to LDL. LDL: Low density lipoprotiens

\begin{tabular}{|l|c|c|}
\hline Triglycerides (mg/dL) & Number & Percent \\
\hline Normal & 38 & 46.3 \\
\hline High & 21 & 25.6 \\
\hline Very high & 23 & 28.0 \\
\hline Mean $\pm S D$ & \multicolumn{2}{|c|}{$164.6 \pm 45.7$} \\
\hline
\end{tabular}

\begin{tabular}{l|c|c|}
\hline HDL (mg/dL) & Number & Percent \\
\hline Normal & 27 & 32.9 \\
\hline Low & 49 & 59.8 \\
\hline Very low & 6 & 7.3 \\
\hline Mean \pm SD & \multicolumn{2}{|c|}{$53.8 \pm 10.3$} \\
\hline
\end{tabular} $\begin{aligned} & \text { TTable/Fig-5]: Percentage distribution of the sample according to HDL. } \\
& \text { HEL: High density lipoprotein }\end{aligned}$

\section{DISCUSSION}

The gall stone disease is known to be clinically identified in middleage group and commonly in females. The mean age in this study is 49.4 and $58.5 \%$ of the patients were in fourth and fifth decade. Various other studies demonstrated similar demographic data [1-3]. In this study, $52.4 \%$ patients were obese, and $35.4 \%$ were diabetic. Dyslipidaemia refers to unhealthy levels of one or more of the three major types of lipid in blood. It could be either a high LDL levels or triglycerides level. It also refers to low HDL levels. Triglycerides are stored in fat cells they are released as and when energy is needed. LDL cholesterol is also known as "bad" cholesterol as this is more atherogenic. HDL is also called "good" cholesterol because it helps to remove LDL from blood. In this study, 42 patients were found to have dyslipidaemia. So, the prevalence derived is $51.2 \%$. The studies found in the literature search shows about half of the study population had dyslipidaemia $[10,12]$.

In this study, 51.2\% were found to have serum cholesterol level above $200 \mathrm{mg}$ which is taken as desirable level. The mean cholesterol level was 216.9. Several studies in the literature also show similar finding $[13,14]$. Lipid profile assessment was also done in this study. There are several studies shows various combinations of different lipids level alterations associated with gall stone. In this study LDL was the most frequently elevated component. LDL level was high (>130 mg) in 42 patients (51.3\%) and $31.7 \%$ had borderline level (100-130 mg). A 29\% had very high level (>160 mg). The mean LDL value is 130.9. Study by Mithal A et al., in 5400 patients also showed that LDL was the most common elevated lipid, which is reported in $48.2 \%$ [15]. There are studies in literature shows increased occurrence of cholesterol stone in patients with high LDL level $[16,17]$ and some studies shows no correlation $[18,19]$. In triglyceride level assessment, 53.7\% had high level (>150 mg) and level was normal in 38 patients with mean value of 164.6. Several studies show similar positive association $[8,18,20]$. Many studies in the literature show that low levels of HDL positively associated with gall stones occurrence $[8,18]$, but in the study population the HDL level mean value was 53.8 and only $7.3 \%$ had the values below the lower range of normal (<40 mg).

\section{Limitation(s)}

Since, study sample was preoperative patients admitted for surgery, it might not represent the actual community prevalence.

\section{CONCLUSION(S)}

Prevalence of dyslipidaemia estimated was $51.2 \%$. Of the fractions of the serum lipids the LDL and triglycerides levels elevations were more commonly detected in patients with gall stones. Majority of patients with gallstones patients were in fourth and fifth decades of life and were females.

\section{REFERENCES}

[1] Stinton LM, Shaffer EA. Epidemiology of gallbladder disease: Cholelithiasis and cancer. Gut Liver. 2012;6(2):172-87. Doi: 10.5009/gnl.2012.6.2.172.

[2] Di Ciaula A, Portincasa P. Recent advances in understanding and managing cholesterol gallstones. F1000Res. 2018;7:F1000 Faculty Rev-1529. Published 2018 Sep 24. Doi: 10.12688/f1000research.15505.1.

[3] Attili AF, Carulli N, Roda E, Barbara B, Capocaccia L, Menotti A, et al. Epidemiology of gallstone disease in Italy: Prevalence data of the Multicenter Italian Study on Cholelithiasis (MICOL). Am J Epidemiol. 1995;141(2):158-65. Doi: 10.1093/oxfordjournals.aje.a117403.

[4] Carey MC. Pathogenesis of gallstones. Am J Surg. 1993;165(4):410-19. Doi: 10.1016/s0002- 9610(05)80932-8.

[5] Wang HH, Portincasa P, de Bari O, Liu KJ, Garruti G, Neuschwander-Tetri BA, et al. Prevention of cholesterol gallstones by inhibiting hepatic biosynthesis and intestinal absorption of cholesterol. European Journal of Clinical Investigation. 2013;43(4):413-26. Doi: 10.1111/eci.12058.

[6] Wang DQ, Cohen DE, Carey MC. Biliary lipids and cholesterol gallstone disease. J Lipid Res. 2009;50(Suppl):S406-11. Doi: 10.1194/jl.R800075-JLR200.

[7] Einarsson K, Hellström K, Kallner M. Gallbladder disease in hyperlipoproteinaemia. Lancet. 1975;305(7905):484-87. doi.org/10.1016/S0140-6736(75)92831-7.

[8] Hayat S, Hassan Z, Changazi SH, Zahra A, Noman M, Zain UI Abdin M, et al. Comparative analysis of serum lipid profiles in patients with and without gallstones: A prospective cross-sectional study. Annals of Medicine and Surgery. 2012;42:11-13. 24 Apr. 2019. Doi:10.1016/j.amsu.2019.04.003.

[9] Weerakoon HT, Ranasinghe S, Navaratne A, Sivakanesan R, Galketiya KB, Rosairo S. Serum lipid concentrations in patients with cholesterol and pigment gallstones. BMC Res Notes. 2014;7:548. doi.org/10.1186/1756-0500-7-548.

[10] Malik AA, Wani ML, Tak SI, Irshad I, UI-Hassan N. Association of dyslipidaemia with cholilithiasis and effect of cholecystectomy on the same. International Journal of Surgery. 2011;9(8):641-42. https://doi.org/10.1016/j.ijsu.2011.08.003.

[11] Expert Panel on Detection, Evaluation, and Treatment of High Blood Cholestero in Adults. Executive Summary of The Third Report of The National Cholesterol Education Program (NCEP) Expert Panel on Detection, Evaluation, And Treatment of High Blood Cholesterol In Adults (Adult Treatment Panel III). JAMA. 2001;285(19):2486-97. Doi: 10.1001/jama.285.19.2486. PMID: 11368702.

[12] Bell GD, Lewis B, Petrie A, Dowling RH. Serum lipids in cholelithiasis: Effect of chenodeoxycholic acid therapy. Br Med J. 1973;3(5879):520-23. Doi: 10.1136/ bmj.3.5879.520. PMID: 4741607; PMCID: PMC1586970.

[13] Chang CM, Chiu THT, Chang CC, Lin MN, Lin CL. Plant-based diet, cholesterol, and risk of gallstone disease: A prospective study. Nutrients. 2019;11(2):335. Doi: 10.3390/nu11020335. PMID: 30720747; PMCID: PMC6412457.

[14] Singh K, Dahiya D, Kaman L, Das A. Prevalence of non-alcoholic fatty liver disease and hypercholesterolemia in patients with gallstone disease undergoing laparoscopic cholecystectomy. Pol Przegl Chir. 2019;92(1):18-22. Doi: 10.5604/ 01.3001.0013.5660. PMID: 32312927

[15] Mithal A, Majhi D, Shunmugavelu M, Talwarkar PG, Vasnawala H, Raza AS. Prevalence of dyslipidemia in adult Indian diabetic patients: A cross sectional study (SOLID). Indian J Endocrinol Metab. 2014;18(5):642-47. Doi: 10.4103/22308210.139220. PMID: 25285280; PMCID: PMC4171886. 
[16] Gu Q, Zhou G, Xu T. Risk factors for gallstone disease in Shanghai: An observational study. Medicine (Baltimore). 2020;99(3):e18754. Doi: 10.1097/ MD.0000000000018754. PMID: 32011459; PMCID: PMC7220401.

[17] Atamanalp SS, Keles MS, Atamanalp RS, Acemoglu H, LalogluE. The effects of serum cholesterol, LDL, and HDL levels on gallstone cholesterol concentration. Pakistan Journal of Medical Sciences. 2013;29(1):187-90. Doi: 10.12669/pjms.291.2798.

[18] Andreotti G, Chen J, Gao YT, Rashid A, Chang SC, Shen MC, et al. Serum lipid levels and the risk of biliary tract cancers and biliary stones: A population-based study in China. Int J Cancer. 2008;122(10):2322-29. Doi: 10.1002/ijc.23307. PMID: 18076041 ; PMCID: PMC2860727.
[19] Tang WH. Serum and bile lipid levels in patients with and without gallstones. $J$ Gastroenterol. 1996;31(6):823-27. Doi: 10.1007/BF02358609. PMID: 9027646.

[20] Jonkers IJ, Smelt AH, Ledeboer M, Hollum ME, Biemond I, Kuipers F, et al. Gall bladder dysmotility: A risk factor for gall stone formation in hypertriglyceridaemia and reversal on triglyceride lowering therapy by bezafibrate and fish oil. Gut. 2003;52(1):109-15. Doi: 10.1136/gut.52.1.109. PMID: 12477770; PMCID: PMC1773519.

\section{PARTICULARS OF CONTRIBUTORS:}

1. Senior Resident, Department of General Surgery, Government Medical College, Thiruvananthapuram, Kerala, India.

2. Associate Professor, Department of General Surgery, Government Medical College, Thiruvananthapuram, Kerala, India.

3. Assistant Professor, Department of General Surgery, Government Medical College, Thiruvananthapuram, Kerala, India.

\section{NAME, ADDRESS, E-MAIL ID OF THE CORRESPONDING AUTHOR}

$S$ Vineed

Ganga, KCRA 66A, Melekariyam, Powdikonam PO,

Thiruvanthapuaram-695588, Kerala, India.

E-mail: vineeds75@gmail.com
PLAGIARISM CHECKING METHODS: Jain Het al.]

- Plagiarism X-checker: Feb 13, 2021

- Manual Googling: May 15, 2021
- iThenticate Software: May 31, 2021 (4\%)

ETYMOLOGY: Author Origin

\section{AUTHOR DECLARATION:}

- Financial or Other Competing Interests: None

- Was Ethics Committee Approval obtained for this study? Yes

- Was informed consent obtained from the subjects involved in the study? Yes

- For any images presented appropriate consent has been obtained from the subjects. NA
Date of Submission: Feb 12, 2021

Date of Acceptance: May 17, 2021

Date of Publishing: Oct 01, 2021
Date of Peer Review: Apr 14, 2021 